\title{
¿Tiene el imputado el derecho a mentir? El derecho a la verdad y el deber de declararla*
}

\author{
Does the imputated have the right to lie? The right to truth and the duty to declare it \\ Gino Augusto Tomás Ríos Patios'
}

Fecha correspondencia:

Recibido: 9 de septiembre de 2019.

Revisión: 4 de octubre de 2019.

Aceptado: 10 de octubre de 2019

Forma de citar:

Ríos, Gino Augusto. ¿Tiene el

imputado derecho a mentir?

Revista CES Derecho. Vol. 10, №. 2,

julio-diciembre de 2019,641- 653

Open access

Términos de uso

Licencia creative commons

Etica de publicaciones

Revisión por pares

Gestión por Open Journal System

DOl: http://dx.doi.org/10.21615/

cesder.10.2.5

ISSN: 2145-7719

Sobre el artículo:

* Documento de reflexión no

derivado de investigación.

Sobre los autores:

1. Doctor en Derecho, Doctor en

Educación, Maestro en Ciencias

Penales, Bachiller en Derecho,

Abogado. Diplomado internacional

en Derechos económicos,

sociales y culturales. Diplomado

internacional en Filosofía

Política. Director del Instituto de

Investigación Jurídica Universidad

de San Martín de Porres en Perú.

\section{Resumen}

En el presente artículo el autor examina la creencia generalizada de que existe el derecho del inculpado a mentir en un proceso penal; analiza simultáneamente la existencia del derecho a la verdad y el deber de decirla; y reafirma el fin axiológico del proceso penal de búsqueda de la verdad para solucionar el conflicto violento subyacente en todo crimen, que es concordante con el interés público de alcanzar la paz social a través de la justicia. Las conclusiones revelan la trascendencia que tiene la verdad para la vida social y contribuyen a mirar desde otra perspectiva el ejercicio de la defensa penal, que ha estado generalmente confundida en trabajar con la falsedad y la mecánica negación en torno a los hechos imputados, cuando debe estar interesada en establecer, interpretar y demostrar los hechos de la manera más cercana a la realidad que sea posible, cuando no desee guardar silencio.

Palabras clave: Derecho a mentir del imputado; derecho a la verdad; deber de decir la verdad; proceso penal.

\section{Abstract}

In this article, the author examines the belief that there is the right of the accused to lie in a criminal proceeding; simultaneously analyzes the existence of the right to the truth and the duty to say it; and reaffirms the axiological purpose of the criminal process of seeking the truth to solve the underlying violent conflict in all crimes, which is consistent with the public interest of achieving social peace through justice. The conclusions reveal the importance that truth has for social life and contribute to look from another perspective at the exercise of criminal defense, which has been generally confused in working with falsity and mechanical denial around the imputed facts, when it should Be interested in establishing, interpreting and demonstrating the facts as close to reality as possible, when you do not want to remain silent.

Keywords: Right to lie of the accused; right to the truth; duty to tell the truth; criminal process.

\section{Introducción}

En estos tiempos, la sociedad contempla la decadencia de determinados valores éticos y el apogeo de las respectivas antinomias en las prácticas de interacción personal y social. En efecto, la honestidad, honradez, lealtad 
a los principios y fines superiores, prudencia, respeto, solidaridad, responsabilidad, humildad, gratitud y sensibilidad, entre otros valores éticos, son virtudes escasas en las relaciones entre las personas y entre éstas y las instituciones.

Al parecer, el individualismo exacerbado, entendido como preferencia personal a obrar según la propia voluntad, sin tener en cuenta la opinión de las demás personas que conforman el mismo grupo y sin considerar las normas de conducta que regulan sus relaciones, ha hecho perder importancia al aspecto axiológico, reemplazándolo por un egoísmo carente de ética para hacer lo que está en su propio interés, sin consideración alguna hacia los demás. Las conductas son, hoy en día, autorreferentes. Se ha entronizado la traición de las esencias y el quiebre de los principios. Esta costumbre actual revela la entronización del consecuencialismo, en el marco del propio interés y el beneficio personal, expresado en la conocida frase "el fin justifica los medios", atribuida erróneamente a Nicolás Maquiavelo, cuando en su obra "El Príncipe" no la menciona textualmente.

La frase alude precisamente a un individuo decidido a hacer cualquier cosa para conseguir o cumplir un objetivo, con lo que desplaza la ética y la moral a posiciones subalternas, justificando los medios falaces que le permiten alcanzar un determinado fin, de tal modo que las acciones humanas deben ser juzgadas por los resultados, por lo que, si el individuo logra sus objetivos, deben de ser aceptados los medios que utilizó.

Pero, semejante postura conductual, según la cual, cuando el fin es lícito, también lo son los medios, desafía los principios éticos, pues los medios usados determinan la naturaleza del fin que es alcanzado, razón por la cual los fines no pueden, de ninguna manera, justificar los medios.

Así, el acto de mentir ante la autoridad judicial en un proceso penal en el que se interviene como imputado, puede eventualmente beneficiar al que miente, con perjuicio de otras personas, por lo cual ese acto es abiertamente perverso por el hipotético perjuicio injustificado que entraña. Además, podría resultar contraproducente por el daño que sufriría quien lo hace, pues al resultar desvirtuada la declaración falaz en virtud de otros medios probatorios, la desvergonzada actitud supondría, de mediar indicios graves de responsabilidad, el sustento para solicitar y ordenar una medida cautelar personal como la prisión preventiva por obstaculizar el proceso; y por otro lado, eliminará la credibilidad en el individuo y si finalmente quedara probada su responsabilidad, quien decide lo tomará en cuenta para agravar la sanción a imponer.

Esta conducta tan reiterada en nuestro medio forense ha dado lugar a la creencia generalizada de que existe el derecho a mentir en favor del imputado. Sin embargo, el autor analiza la verosimilitud de tal aserto y concluye que el acto de decir la verdad es un deber y un derecho de la persona.

En el ejercicio de la defensa judicial en general y particularmente en la defensa penal se observa que existe una inveterada costumbre de negar la responsabilidad en los hechos imputados, merced a la negación de los hechos mismos, lo que incluso supera al ejercicio del derecho a guardar silencio, que resultaría la actitud más sensata para constreñir al Estado o la otra parte si es un proceso civil, a probar los cargos que formula, sin embargo, se prefiere controvertir y contradecir los hechos con la finalidad de dificultar la secuela del proceso y, entretanto, esperar que ocurra 
algo favorable debido a la incompetencia de los operadores de justicia o a la corrupción existente, de donde la mentira deviene en un instrumento útil para obtener una ventaja indebida y oscurecer la averiguación de la verdad aproximativa, que es la finalidad del proceso.

Esta situación problemática es examinada en el presente artículo con los objetivos de desmitificar este pretendido y supuesto derecho a mentir; higienizar y reforzar la ética del derecho de defensa; y revalorar el valor de la palabra de la persona a fin de mejorar el índice de confianza entre los peruanos.

\section{¿El derecho a no autoincriminarse supone el derecho a mentir?}

En principio, el imputado tiene derecho a guardar silencio porque es el Estado el que, al imputarle un cargo, está obligado a probarlo y acreditar su responsabilidad, conforme al principio jurídico según el cual et eo probare oportet ea quae asserit, esto es, quien alega un hecho debe probarlo, lo que constituye el onus probandi o carga de la prueba; y también asume dicha obligación como consecuencia lógica del status jurídico de la garantía y derecho de presunción de inocencia.

El añejo aforismo jurídico según el cual lo normal se entiende que está probado, lo anormal se prueba, es el fundamento del onus probandi, en la medida que quien dice algo que fracciona el estado de normalidad, debe probarlo, en otras palabras, a quien afirma, incumbe la prueba o affirmanti incumbit probatio. Por cierto, romper el estado de normalidad significa alegar y aseverar que se posee una nueva verdad sobre un tema. Es menester destacar aquí que, al fin y al cabo, debe tratarse de una verdad nueva, mas no de una falsedad o mentira, por ello es que de antiguo se descarta la existencia de un supuesto derecho a mentir en el imputado.

Por otro lado, el derecho a la no autoincriminación que tiene el imputado tampoco le faculta a mentir como derecho. El derecho a no reconocer responsabilidad ante el cargo imputado, a no confesar su responsabilidad y a no declarar ser el responsable de los hechos materia de proceso, no significa que deba mentir si desea declarar. Estrictamente, el imputado puede ejercer su derecho a guardar silencio o su derecho a no auto incriminarse, declarando parcialmente, pero no tiene derecho a declarar falsedades, pues ello implicaría utilizar indebidamente un medio oficial de resolución de conflictos que el Estado tiene establecido para todos los ciudadanos, con el objetivo de inocuizarlo, esterilizarlo y, peor aún, hacer daño a la otra parte, dificultando e impidiendo la acción correcta de la justicia.

De otra parte, el carácter científico del Derecho también abona para descartar la existencia de un derecho a mentir del imputado. En efecto, el Derecho es ciencia en tanto el empleo de determinados métodos y conocimientos conduce a la creación de más conocimiento objetivo, a modo de pronósticos delimitados, cuantitativos y comprobables, expresados a través de razonamientos, referidos a actos y hechos pretéritos, presentes y futuros, que se estructuran en reglas o normas generales, los cuales informan la actuación de un sistema y anuncian cómo actuará en determinados casos. El Derecho es ciencia social porque sirve al hombre y éste es el eje central de su esencia. El campo pluridimensional del Derecho es el material, formal, jurídico, político, sociológico y valorativo.

En esa línea, el habilitar la mentira como si fuera un derecho, trastocaría y enrarecería el funcionamiento del sistema, haciéndolo más lerdo y odioso, generaría más conflicto que aquel que se propone solucionar. El interés y el fin de toda ciencia es, 
también como en el proceso, la búsqueda de la verdad. Por ello, la mentira no es legítima.

En el campo procesal, el Derecho es una de las soluciones racionales posibles para dirimir conflictos intersubjetivos de intereses con relevancia jurídica, cuando se presenta una violación de los preceptos legales, cuando hay una insatisfacción jurídica, una disconformidad entre la ley y la realidad, debe buscarse un medio para gestionar, solucionar y resolver el conflicto.

Evidentemente, la falsedad no tiene cabida en este medio heterocompositivo racional y de carácter científico, pues perturbaría y dificultaría el fin que es la búsqueda de solución al conflicto. El derecho de defensa debe ejercerse, conforme se enseña a los futuros abogados, con base en la diferente interpretación jurídica de los hechos que el material probatorio acredite, para que el magistrado decida si el acto se subsume o no en el presupuesto normativo.

En la ciencia del Derecho en general y del derecho procesal en particular, los sujetos procesales deben guiarse por un código ético forense de comportamiento.

La ética debe ser tomada en serio y aplicarse al proceso honrando y contribuyendo a su finalidad, sin ser vista como un campo de lucha sin cuartel y sin escrúpulos.

El derecho a no confesarse culpable, a no auto incriminarse, no debe ser entendido como la posibilidad de mentir, sino tan solo poder optar por guardar silencio, que es otro de los derechos que tiene el imputado o de declarar parcialmente y no totalmente, que también es su derecho. Sin embargo, las gentes creen entender que mentir es una facultad básica que tiene el imputado, pero ello no es más que un error, un exceso, pues el hecho de inventarse una historia que no tiene nada que ver con los hechos, ya es demasiado incompatible con el Derecho.

De tal manera que el derecho a no decir la verdad o el derecho a mentir no forma parte ni tiene vinculación alguna con el derecho a no declarar contra uno mismo y el derecho a no confesarse culpable. En su defensa el imputado tiene derecho a guardar silencio o a declarar, si hace esto último tiene derecho a no auto incriminarse y a que no se le coacte.

Dentro de este marco, debe actuar con ética, que es la obligación moral de toda persona en una sociedad. El hecho de que esté facultado a guardar silencio si lo desea, que esté facultado a no auto incriminarse si así lo decide o que no deba ser coactado en su declaración, no significa que pueda mentir, que deba faltar a la verdad, pues debe contribuir a la búsqueda de la verdad o, cuando menos, no debe falsearla. No es que pueda decir cualquier cosa, ello sería irresponsable éticamente e irresponsable de cara a la finalidad del proceso. El hecho de no mentir tampoco merma su derecho a la defensa, ya que tiene la opción de guardar silencio y dejar toda la carga de la prueba al representante del Ministerio Público. Ir más allá de esas posibilidades implica apartarse del recto ejercicio del derecho de defensa.

En resumen, el Estado debe hacer su esfuerzo en buscar la verdad durante el proceso para resolver el conflicto subyacente. El imputado debe hacer su esfuerzo por colaborar con la búsqueda de la verdad y que, en el peor de los casos, si es responsable, que ésta le acarree una consecuencia menos grave o no tan grave. El Estado no debe poner toda su energía y recursos en falsear la verdad para castigar al imputado 
mediante un proceso desviado pleno de pruebas falsas e interpretaciones antojadizas, como tampoco el imputado debe proceder con cinismo y descaro al declarar ante el funcionario judicial. Del mismo modo, el imputado no debe extremarse en falsear la verdad de los hechos o las pruebas a su favor. Si es consciente de su responsabilidad puede, en el mejor de los casos, guardar silencio, para no ir contra sus intereses, dejándole toda la carga de la prueba al Estado, pero no debe mentir porque no tiene derecho a ello y no tiene derecho porque es éticamente reprobable, por tanto, el orden jurídico no puede reconocer un derecho a partir de una infracción ética.

No hay error en considerar que el interés del Estado y del imputado en un proceso es el mismo y está dado por la búsqueda de la verdad y la realización de la justicia, desde sus respectivas posiciones. La no comprensión de esto dificulta la construcción de un mejor estado de cosas en la relación Estado-ciudadano. Por ello, el imputado consciente de la comunión de intereses, que declara la verdad y acepta su responsabilidad es recompensado por el Estado atenuando su débito penal, lo cual también demuestra que mentir no es un derecho, ya que de lo contrario no podría recompensarse al que no miente porque se afectaría al que ejerciera su derecho a mentir y se enviaría un pésimo mensaje social.

Por el contrario, como no existe el derecho a mentir, el Estado premia al imputado que colabora con la verdad. Al que no lo hace, porque no es consciente de la similitud de su interés con el del Estado en el proceso penal o porque subordina el interés social de hallar la verdad de un conflicto no dirimido a tiempo por vías pacíficas a su personal beneficio, provecho y utilidad, le aplicará la ley sin atenuantes.

\section{El derecho a la verdad y el deber de declararla}

\section{El derecho a la verdad}

El epígrafe, en este caso, está referido no al derecho fundamental autónomo ante una grave violación de los derechos fundamentales, sino al derecho que tienen los justiciables de que ésta, en su versión aproximativa, sea hallada como resultado del proceso. Ambas partes procesales tienen ese derecho porque es a través de la búsqueda de la verdad, como vehículo para que el proceso cumpla su finalidad de resolver el conflicto sometido a la decisión jurisdiccional, la decisión se plasmará en justicia, evitando los excesos.

Además, es un derecho social cuyo correlato es un deber del Estado para resolver un conflicto con justicia. Hay, pues, un interés público en la finalidad del proceso y en el medio para llegar al fin de discernir justicia, cual es, la verdad.

En esa línea, la palabra verdad comprende la honestidad, la buena fe y la sinceridad; también el acuerdo del conocimiento con lo que se afirma como realidad.

El concepto de honestidad recogido por el Diccionario de la lengua española (2014) proveniente del latín honestitas, que significa honradez, es la virtud definida como decir la verdad, ser decente, recto, razonable, íntegro y justo, es decir, no mentir. El concepto, como se puede deducir fácilmente, alude al respeto que debe tener toda persona sobre todas las cosas y las normas que la sociedad en la que se habita considera correctas y adecuadas. La honestidad es, en otras palabras, el respeto a la verdad en relación con los hechos y las personas, esto es, en la interacción social. 
En el mismo sentido, la buena fe, proveniente del latín bona fides, es un principio jurídico general que consiste en el estado mental de honradez, de convicción en cuanto a la verdad o exactitud de un asunto, hecho, opinión o la rectitud de una conducta, con relación a las partes interesadas en los hechos en los que se participa. Por su relación con el proceso judicial, se le conceptúa como un atributo jurídico de la conducta legalmente exigida en el proceso con rectitud e integridad, evitando las actuaciones abusivas de las partes, por lo que determina el ejercicio de los derechos conforme a los requerimientos éticos y sociales.

Como se puede apreciar, la verdad está asociada estrechamente a lo recto, igual que el Derecho mismo, vocablo que viene del latín directum, que significa lo que está conforme a la regla, a la norma o, como expresa Villoro Toranzo (2005), aquello que no se desvía ni a un lado ni otro, esto es, lo recto.

Apartarse de la verdad, aún en un proceso judicial, implica relativismo ético, el cual reduce la verdad a lo que nos satisface o no, según nuestro interés personal, en vez de basar las decisiones en lo correcto, como apunta Vigil, Jorge (1995) y ahí surge el problema, porque ello nos conduce irremediablemente al todo vale, que se plasma en la vida social con el epíteto nada está mal en última instancia si puedes salirte con la tuya, lo que da lugar al consecuencialismo, corriente ética que postula que la bondad o maldad, esto es, el apartarse o no de la verdad la establece el propio sujeto en función de las consecuencias que prevé. En otras palabras, la propia declaración la juzgará buena el mismo declarante si le origina el mayor bien posible o un excedente de la cantidad de bien sobre el mal.

El grave problema ético social de aplicar este modo de proceder, consiste en que la noción de dignidad humana se afecta y resquebraja pues pasaría a gobernar el interés propio, ya no la razón, distintiva de la especie humana, con lo cual nuestra interacción en la sociedad será cuestionable.

Es un esencial imperativo ético la búsqueda del bien, por tanto, partiendo de este punto se debe aceptar que decir la verdad es la expresión del buen obrar que impide la degradación del ser humano como ser social por naturaleza y permite evitar daños más graves, empodera la credibilidad, sincera la realidad y tranquiliza el espíritu para emprender mayores obras.

La declaración del imputado está regulada por los artículos 86 al 89 del Código Procesal Penal (CPP). Destaca, en primer lugar, el precepto según el cual, como anota Pérez-Cruz, M. (2011) la declaración del imputado es un acto voluntario que cuando se realiza constituye un medio procesal amplio por estar vinculado al derecho de defensa material para manifestar su conocimiento acerca de los cargos y hechos de los que se le pregunte o quiera referir en una declaración o más declaraciones, de acuerdo con su propia idea de oportunidad y de optimizar sus posibilidades en el proceso, sin que ellas constituyan algo malicioso, abusivo, dilatorio o notoriamente impertinente, pues ningún derecho es, en la praxis, absoluto.

Asimismo, la declaración del imputado-inculpado ante el Fiscal es imprescindible, aun cuando haya declarado ante la Policía; también lo es en sede del juicio oral, cuando tiene la condición de acusado, siendo lo primero a actuar en el debate probatorio, según los artículos 375.1, a; y 376 del CPP. En ambas oportunidades, se hará en presencia de abogado defensor, por ser un acto de defensa necesaria que forma parte de la garantía de defensa procesal. 
Como se puede observar, en ningún momento los artículos acotados, como ninguna otra normativa, confieren o se refieren al derecho a mentir que tiene un imputado. Se trata de una ficción, ni siquiera de una deducción válida de los otros derechos con los que cuenta el imputado, como son el de guardar silencio, el de no auto incriminarse y el de no ser coaccionado. Es un mito forense peligrosamente extendido a lo popular, pues si se puede mentir ante una autoridad del sistema penal, con mayor razón se puede hacerlo en otros ámbitos, con lo cual el valor de la palabra desaparece y el nivel de conflictividad en la interacción social se incrementa.

\section{El deber de declarar la verdad}

A juicio del autor, lo más importante a los efectos del articulado antes indicado, es la facultad de exhortación del fiscal o juez que le hacen al imputado, inculpado o acusado, en el sentido de la necesidad de que responda con claridad y precisión, así como, excepcionalmente, informarle de los beneficios premiales por una cooperación al debido esclarecimiento de los hechos, según el artículo 87.4 del CPP. Si la verdad es la coincidencia del pensamiento con los hechos de la realidad y la precisión es el ajuste completo o la fidelidad de un dato o expresión, entonces fuerza es deducir que el imputado tiene el deber de decir la verdad, lo cual le significará beneficios en términos de atenuante $u$ otros del derecho premial.

Como refiere Jauchen, E. (2012) el interrogatorio debe ser objetivo y no coactivo, sin preguntas ambiguas, capciosas o sugestivas, presiones o amenazas; asimismo que, conforme declare, indique cuáles actos o documentos pueden consolidar su versión. En ese sentido, el artículo 89.1 del CPP preceptúa que el imputado declarará sin ataduras y, si está privado de libertad, en un recinto cerrado para impedir la fuga 0 que atente contra la seguridad de los demás, lo cual se contempla para no afectar la presunción de inocencia a que tiene derecho.

Es menester enfatizar que la declaración sobre el hecho imputado consiste en una versión libre del imputado, lo cual no significa que tenga derecho a mentir, sino que es libre en la medida que es voluntaria -si desea la hace o no- y debe estar exenta de coacción, siendo posible que el fiscal o el juez formulen observaciones precisas y oportunas respecto de lo que indica, de su pertinencia y de su limitación a hechos y circunstancias del caso.

Por otro lado, el derecho al silencio que tiene el imputado, que también forma parte de la garantía de defensa procesal, implica que él tiene el dominio de lo que dice y lo que no dice, pudiendo ser total o parcial, es decir, guardar silencio absoluto o someterse a interrogatorio integralmente o parcialmente o declarar solo ante algunas partes procesales o contestar solo algunas preguntas. Estas son las formas que puede optar el imputado para ejercer su derecho de defensa, pero no puede mentir.

El derecho que tiene de no ser obligado a auto incriminarse lo puede ejercer haciendo uso de las variables antes señaladas. 0 guarda silencio y no declara o lo hace de manera libre, voluntaria, total o parcialmente, a todos o a algunos, sin coacción, pero declarando con claridad y precisión. Pero no puede mentir, pues él también está interesado en que se llegue a la verdad al fin del proceso, para beneficiarse con ella. Recuérdese que, como afirma Moreno, V. y Cortés, V. (2005) nadie está en mejor conocimiento de los detalles y pormenores de los hechos que el propio autor de los mismos, debido su intervención personal y directa en la materialización de los mismos, de donde se puede derivar su responsabilidad o no culpabilidad. Hay aquí una 
razón adicional para que declare la verdad, pues le consta personalmente, en aras de arribar a la verdad y hacer justicia.

A mayor abundamiento de la posición sostenida en este artículo sobre la inexistencia del derecho a mentir del inculpado, se tiene que cuando hay contradicciones objetivas entre lo declarado en distintas oportunidades, todas con garantías plenas, se requerirá de una confrontación, una lectura y un interrogatorio específico al acusado para que explique el cambio de versión. La razón no es otra que la completa elucidación de los hechos. Una vez más se verifica que no tiene derecho a mentir. En la praxis podrá hacerlo, pero no es un derecho que le asiste.

Históricamente, el supuesto derecho a mentir tampoco ha existido. En efecto, a partir del momento en que el juicio sustituye a la autodefensa, en el proceso se confrontan la imputación-acusación y la defensa, cuya construcción hacía evidente para el juzgador la verdad del caso, con lo cual el mensaje subyacente era que las partes contribuían a la justicia con sus declaraciones, verdaderas o falsas, ante las cuales el magistrado tenía la obligación de no creer y cualquier fingimiento, devenía inocuo, excepto para quien perdía la litis.

En Roma, las legis actiones, al igual que en el procedimiento formulario, establecieron las penas procesales (poenae temerae litigatum) o el sistema llamado litis crecencia por Infitatio (negación de deuda), en el cual, si perdía el juicio, evidentemente por falsear la verdad de la deuda, debía pagar el doble de la deuda.

Otro antecedente del deber jurídico de decir la verdad en juicio, es el solemne juramento de calumnia romano, donde se obligaba a no negar el derecho del actor en forma artera o temeraria.

El derecho romano, el derecho canónico, el Fuero Juzgo y las Leyes de Indias, también contemplaron el deber de decir la verdad en el proceso. Couture, E. (1979) asevera que no ha existido en nuestros países, expresamente, un deber jurídico y moral de decir la verdad.

No obstante, es menester recordar que, en el proceso civil, el Código de Procedimiento Civil venezolano, establece para las partes y los terceros intervinientes en el proceso, una serie de obligaciones, entre las cuales destacan las siguientes:

Artículo 17. El Juez deberá tomar de oficio o a petición de parte, todas las medidas necesarias establecidas en la ley, tendentes a prevenir o a sancionar las faltas a la lealtad y probidad en el proceso, las contrarias a la ética profesional, la colusión y el fraude procesales, o cualquier acto contrario a la majestad de la justicia y al respeto que se deben los litigantes.

Artículo 170. Las partes, sus apoderados y abogados asistentes, deben actuar en el proceso con lealtad y probidad. En tal virtud deberán:

$1^{\circ}$ Exponer los hechos de acuerdo con la verdad.

$2^{\circ}$ No interponer pretensiones ni alegar defensas, ni promover incidentes, cuando tengan conciencia de su manifiesta falta de fundamentos; 
$3^{\circ}$ No promover pruebas ni realizar, ni hacer realizar, actos inútiles o innecesarios a la defensa del derecho que sostengan.

Parágrafo Único: Las partes y los terceros que actúen con temeridad o mala fe son responsables por los daños y perjuicios que causaren.

Se presumen, salvo prueba en contrario, que la parte o el tercero han actuado en el proceso con temeridad o mala fe cuando:

$1^{\circ}$ Deduzcan en el proceso pretensiones o defensas, principales o incidentales, manifiestamente infundadas;

$2^{\circ}$ Maliciosamente alteren u omitan hechos esenciales a la causa;

$3^{\circ}$ Obstaculicen de una manera ostensible y reiterada el desenvolvimiento normal del proceso.

Huelgan los comentarios ante las elocuentes prescripciones del citado código.

Por otro lado, el Código Penal de Guatemala, aprobado mediante Decreto N 17-73, en su artículo $459^{\circ}$ tipifica el delito de perjurio, que lo comete quien, ante autoridad competente, jurare decir la verdad y faltare a ella con malicia.

En el Perú se encuentra tipificado el delito de falsedad genérica, que es un tipo penal residual, solo aplicable a los hechos que no estén subsumidos en los presupuestos normativos de los tipos penales contra la fe pública, según lo dispuesto por el artículo 438 del Código Penal, en virtud del cual no sólo es posible cometer este delito a través de un documento, sino que puede realizarse mediante palabras, hechos o cualquier medio, siempre que se trate de una simulación, suposición o alteración de la verdad y cause un perjuicio a terceros, por lo que resulta que se está penando la mentira como componente indispensable e intrínseco de la acción punible, es decir, de la conducta misma.

Se entiende entonces que la mentira está penada y que aun cuando el imputado puede mentir, corre el grave riesgo de incurrir en el delito de falsedad genérica, con o cual queda demostrado que no existe el derecho a mentir del imputado, es tan solo una posibilidad fáctica que tiene en el ejercicio de su derecho de defensa, más no un derecho. Por el contrario, lo que existe es el deber ético de decir la verdad y el derecho de conocer la verdad legal a través del proceso, con la finalidad de decidir en justicia y solucionar un conflicto de intereses.

Entonces a estas alturas ya ha quedado claro que no es ético ni razonable pervertir los elementos fácticos que vinculan a las partes en la relación procesal, con la finalidad de obtener una decisión jurisdiccional favorable. Incurrir en dolo procesal, mediante la mentira y el engaño, para obtener fines distintos a los del proceso es alienar su finalidad y condenar al proceso a su destrucción e implica mala fe y temeridad.

Repárese en que el Estado no somete a disposición de las partes procesales, el fino engranaje judicial, para que sea usado como mejor les parezca, o sea, mintiendo ladina y deslealmente, para encubrir sus propios fraudes. Pregúntese cada quien ¿Qué es declarar mentiras en un proceso sino un fraude a la ley? 
Por lo expuesto, es palmario que el Estado tiene el inexcusable deber de impedir en general la litigación temeraria, la mala fe y el dolo procesal, y en particular que en el proceso el imputado declare mentiras, pues ello es contrario al orden público y tornaría torcido el Derecho. Es pues un deber de las partes decir la verdad en el proceso y simultáneamente una obligación del Estado sancionar dicha inconducta. Esto es lo que define la validez de una respuesta negativa a la interrogante que encierra la pregunta del título de este artículo, negación que sirve para moralizar el proceso y también higienizar y hacer más ético el ejercicio del derecho de defensa.

\section{La verdad en el proceso penal}

De lo que tenemos dicho en este artículo, se desprende indefectiblemente que el imputado tiene el derecho a guardar silencio, el derecho a declarar total o parcialmente, el derecho a no auto incriminarse y el derecho a declarar sin coacción alguna, pero de ninguna manera tiene el derecho a mentir. En la práctica es posible que lo haga, sin que le asista derecho a ello, pero ello no significa que su derecho de defensa lo deba ejercer mintiendo. No podría alegar una vulneración al derecho de defensa ni al derecho a la tutela jurisdiccional efectiva, por ejemplo, en esos términos.

Reiteramos que no tiene derecho a mentir porque las partes en el proceso deben actuar con buena fe, probidad y lealtad procesal, acusando y defendiendo con base en pruebas reales y no fabricadas ex profeso, en interpretaciones jurídicas de los hechos y no en narraciones arbitrarias y ficticias, pues con ello estarían haciendo fraude procesal y colocando a la institución procesal en un rol no compatible con su finalidad, como es la de solucionar un conflicto intersubjetivo de intereses de acuerdo con la verdad aproximativa y la justicia, para alcanzar la paz social.

En efecto, declarar mentiras en el proceso, esto es, presentar los hechos de manera distinta a como acontecieron realmente, con la torva intención de evitar una declaración de responsabilidad, es actuar dolosamente, con total convicción de provocar error en el magistrado.

Al recordar que Alfred Tarsky (1991, p. 275) define el concepto de verdad como la correspondencia entre las aserciones referidas a los hechos del mundo empírico y lo ontológicamente ocurrido en él; y que Luigi Ferrajoli (2006, p. 48) adhiere a dicha definición; se comprueba que el concepto de verdad está íntimamente ligado al de la justicia de la decisión, dicho del modo más pragmático posible, es indudable que dicha decisión debe ser siempre sensata, prudente y razonablemente justa, lo cual nos remite indefectiblemente a la verdad de los hechos probados en el proceso.

Efectivamente, concordando con Taruffo, M. (1997, p. 317) una decisión judicial será justa si es el corolario de un proceso justo; si es consecuencia de la recta interpretación y aplicación de la norma pertinente; y si se han determinado y probado previamente los verdaderos hechos. Nuevamente, la verdad en el proceso aparece como un dato indispensable a respetar por la trascendencia que tiene en el orden social, que es el espacio natural de destino del resultado del proceso. Esa trascendencia no es otra que la paz social.

Es que, coincidiendo nuevamente con Taruffo, M. (1997, p. 418) la verdad es un valor ético que hace inadmisible un sistema moral que legitime la falsedad en cualquiera de sus formas; es también un insumo político de la democracia liberal porque la política debe asumir un acuerdo social verdadero entre toda la ciudadanía; y tiene, asimismo, un valor jurídico, desde que para ejercer un derecho, como es el derecho 
de la acción o el derecho de defensa, la persona debe reunir las condiciones fácticas que la ley acepta para consagrar tal derecho, como sostiene también Taruffo, M. (2012, p. 44), siendo que ninguna ley otorga el derecho de mentir en un proceso.

El proceso judicial es una empresa social que necesita de verdades suficientes para proporcionar una plataforma prudentemente fundada para la toma de la decisión que solucione el conflicto. No es una palestra inescrupulosa de falacias para hacer incurrir en error al Estado. En tal medida, no existe impedimento para alcanzar la verdad, por el contrario, existen suficientes razones que justifican su búsqueda, entre las cuales destaca la justica de la decisión final, en la que todos los ciudadanos creemos por haber acordado en el pacto social hacerlo.

La obligación de decir la verdad, analizada jurídicamente, se asienta en que el respeto o violación de dicho precepto se califica como honradez o fraude, cuya correspondencia en la moral es, respectivamente, verdad y mentira.

\section{Conclusiones}

La ética apunta a la búsqueda del bien. Es el camino del buen vivir. Es evidente que no se puede vivir con mentiras, por eso éticamente es preciso conocer y respetar la verdad. Ella es un fundamento principal de la ética, pues es la adecuación y conformidad entre la realidad y el entendimiento o conocimiento, el modo como el hombre se relaciona cognoscitivamente con la realidad, que nos permite aprehender las cosas como son.

La verdad dota de sentido la vida social porque confiere respeto entre las personas, constituyéndose como pilar sobre el que se asienta la conciencia moral de la sociedad. Pero la verdad no es algo puramente intelectual, es decir, no es un producto exclusivo ni único de la pura razón, con ella se implica la vida entera del hombre, pues es él quien la declara y quien cree en ella.

La veracidad es exigencia ética esencial de la existencia humana, solo posible mediante la coexistencia y convivencia con los demás. No hay nada tan destructivo para las relaciones interhumanas como la falta de verdad y la mutua desconfianza. Es una actitud ética global de la existencia del ser humano, sin la cual no tendría sentido ni la vida personal ni la relación interpersonal. Es la única manera, además, de adecuar las acciones hacia el bien y unificar los propósitos a los actos.

Al surgir un conflicto violento, como es el crimen y someterlo a la potestad estatal de componerlo discerniendo justicia, se hace imprescindible contar con la verdad de ambas partes para resolverlo razonablemente en aras de restaurar la paz rota. Si en ese proceso, en el que interviene el Estado como tercero imparcial, precisamente para que no se adopten medidas privadas de hacer justicia vengativa, por mano propia, una de las partes, a quien se le atribuyen los cargos, declara mentiras respecto de los hechos investigados, jamás se llegaría a la verdad ni a la justicia ni a la paz social.

No es posible imaginar un proceso plagado de mentiras, en el que las partes se creen con derecho a mentir. Sería una visión surrealista y francamente alienada y demente por su irracionabilidad. De ahí que no pueda sostenerse la ficción de que existe un derecho a mentir del imputado. No sería legítimo. Hacen mal quienes así lo creen y derivan de los verdaderos derechos que asisten al imputado, como el de defensa, de guardar silencio, de no auto incriminarse y de no ser coaccionado al declarar, con los 
cuales el mentir no tiene ninguna vinculación. Ninguna norma jurídica lo reconoce por lo demás. El mito en nuestro sistema judicial se basa en que no se le toma juramento al imputado-acusado cuando desea declarar, a diferencia de lo que ocurre en el sistema judicial anglosajón, en el cual el imputado tiene derecho a declarar la verdad, pero presta juramento, razón por la cual si miente en esta condición incurre en el delito de perjurio.

En los países como el Perú, que no tienen tipificado el delito de perjurio pero si el de falsedad genérica, el imputado que miente al declarar libre y voluntariamente, es decir, luego de renunciar al derecho que tiene a guardar silencio y no siendo obligado a auto incriminarse, lo cual no excluye que confiese voluntariamente su responsabilidad, incurriría en este tipo penal, pues su conducta estaría subsumida en el presupuesto fáctico de la norma penal; lo cual quiere decir que la mentira es sancionada si causa perjuicio a terceros, por lo que es un hecho que no existe el derecho a mentir del imputado, tan solo la posibilidad fáctica de hacerlo bajo riesgo de incurrir en delito de falsedad genérica si se le prueba lo contrario, sino por el contrario, existe el deber ético de decir la verdad, no la obligación legal; y el derecho a la verdad, indispensable para solucionar un conflicto de intereses.

Concluyentemente, el derecho a la defensa tiene que ejercerse honestamente, con sujeción a la ética, que es la base del derecho, por lo que excluye la mentira, la cual es de hecho una posibilidad del imputado en el proceso como lo es de toda persona en su vida. Evidentemente, quien opta por ser deshonesto incurriría en el delito de falsedad genérica si ello causa perjuicio a terceros. Hay, pues, un deber ético de declarar (decir) la verdad, más no una obligación legal, sin embargo, como se ha visto en el desarrollo del presente artículo, el fiscal o el juez, según la estación procesal, tienen la atribución de exhortar al imputado o acusado en el sentido de hacerle ver la necesidad de que responda con claridad y precisión.

En definitiva, si las personas recuperasen el buen hábito, propio de una vida ética, de vivir del lado de la verdad, recobrarían la auto estima, el valor de la palabra, disminuiría la conflictividad y el derecho de defensa volvería a ser un sano ejercicio dialéctico del conocimiento jurídico y un valioso instrumento de higienizar la praxis forense. No admitirlo es cohonestar y auspiciar la mentira.

\section{Referencias}

Código Penal del Perú. Disponible en: http://www2.congreso.gob.pe/sicr/cendocbib/con5 uibd.nsf/001CD7E618605745052583280052F800/\$FILE/COD-PENAL actualizado 16-09-2018.pdf

Código Penal de Guatemala. Disponible en: https://www.acnur.org/fileadmin/ Documentos/BDL/2001/0136.pdf

Congreso de la República de Venezuela (1990) Código de Procedimiento Civil Venezolano. Edición oficial. Disponible en: https://www.wipo.int/edocs/lexdocs/ laws/es/ve/ve044es.pdf

Couture, E. (1979). Estudios de Derecho Procesal. 3ra. Edición. Buenos Aires, Argentina: Editorial Depalma.

Ferrajoli, L. (2006) Derecho y Razón. $8^{\circ}$ edición. Madrid, España: Editorial Trotta. 
Granja Castro, D. M. Y Charpenel Elorduy, E. (2012). Kant y el escandaloso tópico de la prohibición de mentir: una lectura alternativa desde la filosofía del derecho. ÉNDOXA: Series Filosóficas, №29, pp.15-44.

Jauchen, E. (2012). Tratado de Derecho Procesal Penal III, Santa Fe, Argentina: Rubinzal - Culzoni Editores.

Moreno Catena, V. Y Cortés Dominguez, V. (2005) Derecho Procesal Penal. Madrid, España: Tirant lo Blanch.

Pérez-Cruz, M. (2011). La declaración del imputado. Madrid, España: Editorial Civitas.

Presidencia de la República (2004). Código Procesal Penal Del Perú. Edición oficial. Disponible en: http://spij.minjus.gob.pe/content/publicaciones oficiales/img/ CODIGOPROCESALPENAL.pdf

Real Academia Española (2014). Diccionario de la lengua española. 23ª edición. Madrid, España: Espasa

Tarsky, A. (1991). La concepción semántica de la verdad y los fundamentos de la semántica. Madrid, España: Valdéz Villanueva.

Taruffo, M. (1997) Idee per una teoria della decisione giusta. Rivista Trimestrale di diritto e procedura civile, núm. 2, 1997. pp. 315-329.

Taruffo, M. (2012). Proceso y decisión. Lecciones mexicanas de derecho procesal. Madrid, España: Marcial Pons.

Vigil Rubio, J. (1995). Compendio de Ética. Madrid, España: Alianza Editorial.

Villoro Toranzo, M. (2005). Introducción al estudio del Derecho. México, México: Porrúa. 